\title{
Pelvic Kidney Mimicking Skeletal Metastasis on Bone Scan- Interesting Image
}

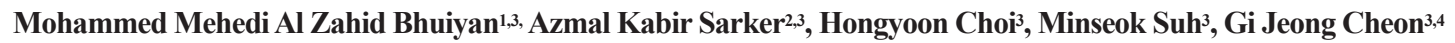 \\ Institute of Nuclear Medicine and Allied Science, Sylhet \\ 2Institute of Nuclear Medicine and Allied Science, Mitford, Dhaka \\ 32Department of Nuclear Medicine, Seoul National University College of Medicine, Seoul, Korea \\ ${ }^{4}$ Cancer Research Institute, Seoul National University College of Medicine, Seoul, Korea
}

Correspondance Address : Dr. Mohammed Mehedi Al Zahid Bhuiyan, Assistant Professor \& SMO, INMAS, Sylhet \& KOICA fellow, Department of Nuclear Medicine, Seoul National University Hospital, South Korea. zahidssmc36@gmail.com

\begin{abstract}
A 57-year-old female patient underwent left breast-conserving surgery with sentinel lymph node biopsy for Left breast carcinoma (stage IIA). The patient had hypertension and diabetes mellitus. Other findings include multiple hepatic cyst, bilateral renal cysts and uterine myoma. She had no significant renal symptoms and her liver \&renal function test were normal.She was sent for Technetium-99m-methylene diphosphonate ( $99 \mathrm{~m}$ Tc-MDP) bone scan. There was a large area of intense tracer concentration in the region of right sacro-iliac (SI) joint which appeared like an osteoblastic metastasis at first glance. However, absence of uptake in the right renal fossa with the left kidney being normal in position contemplated the probability of right-sidedpelvickidneywhich was confirmed later by a contrast enhanced computerized tomography (CT) scan of abdomen that showed a pelvic right kidney overlying the sacrum.
\end{abstract}

Key words: Ectopic kidney, Pelvic kidney, Tc-99m-MDP, Bone scan, CT Bangladesh J. Nucl. Med. Vol. 22 No. 2 July 2019

DOI: https://doi.org/10.3329/bjnm.v22i2.51770

\section{INTRODUCTION}

\section{Image interpretation:}

There is a large area of intense tracer uptake in the region of right sacro-iliac (SI) joint (black arrow) with tracer concentration in rest of the skeletal system being symmetrical and within normal limits. However, the right renal fossa was empty with the left kidney being in normal position.

Contrast-enhanced CT abdomen (E, F) demonstrated the right kidney to be mal-rotated, anterior to sacrum near the right SI joint area (yellow arrow)and an empty right renal fossa. The right renal artery was a posterior branch of aorta adjacent to aortic bifurcation while the right renal vein drained near the bifurcation of common iliac vein.

\section{DISCUSSION}

The incidence of the pelvic kidney is reported as 1:2100-1:3000 in autopsy series (1) although the exact incidence may be difficult to determine because of the clinically silent nature in many cases. The position may be anywhere from the pelvis to the thorax, with varying axis and placement. The anomaly occurs more commonly in males (2:1), and 3 times more common in the left side (2). Pelvic kidney results from complete failure of ascension during development (3). Half of the patients develop hydronephrosis due to mal-rotation of the kidney and anteriorly placed renal pelvis leading to impaired urinary drainage (4). Reportedly, there are a number of variability in the vasculature of pelvic kidney which are crucial for surgical planning $(5,6)$. Ectopic kidney is usually of no other clinical significance (1) although renal cell cancer in ectopic kidney has been reported (7).

The ectopic position of the kidneys, especially within the bony pelvis, complicates the interpretation of imaging modalities like computed tomography (CT), ultrasound, and conventional radiography (8). Bone scintigraphy using $99 \mathrm{mTc}$ MDP is widely used to detect abnormal osteoblastic activity in various diseases especially to detect bony metastases. This radiopharmaceutical is excreted through the kidney so that it is possible to comment on the location of the kidneys (9). SPECT/CT can be useful instead of planar scan for differentiation of metastases in bony pelvis or sacroilitis in a patient with ectopic pelvic kidney. 


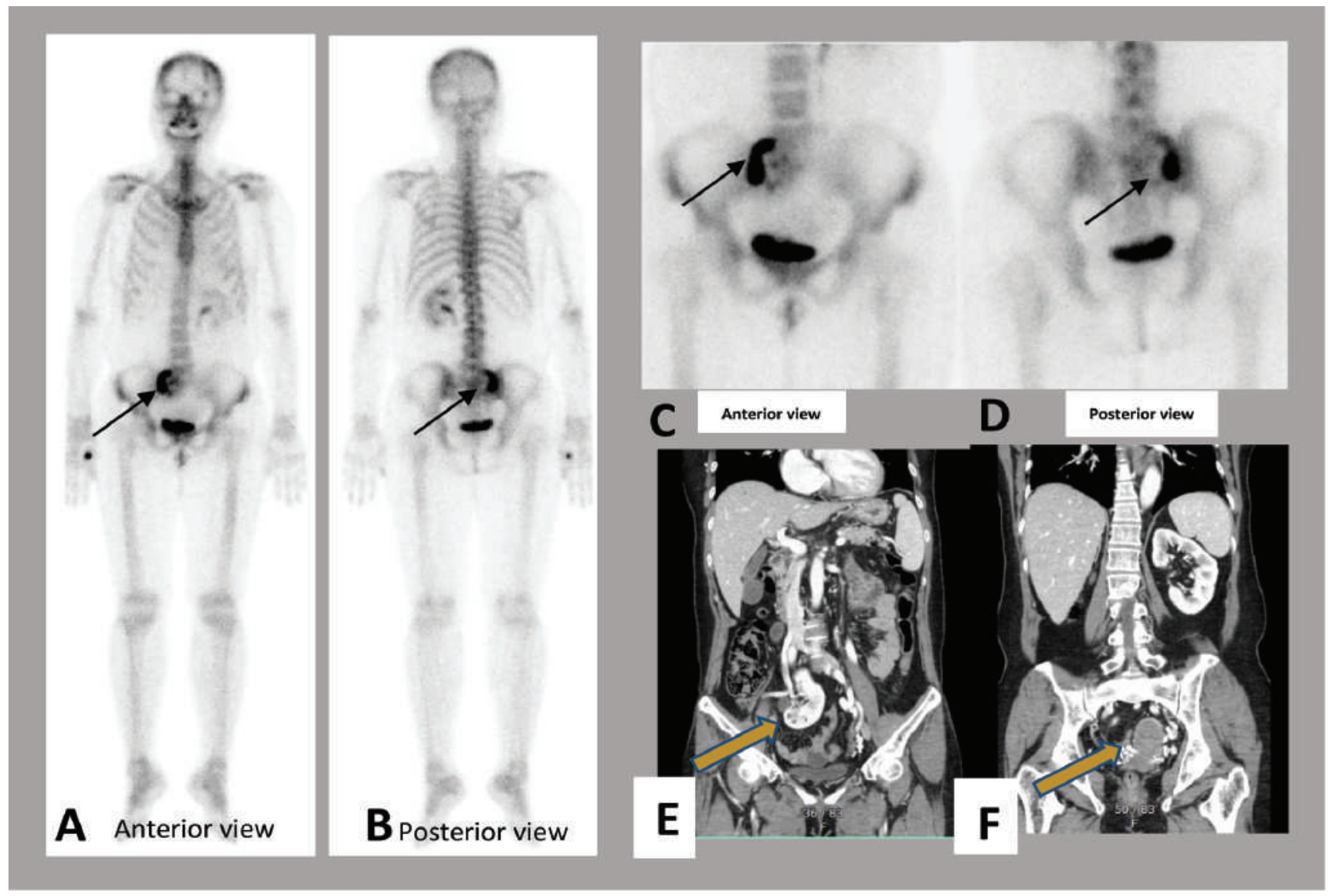

Figure 1: Whole body sweep images (A, B,) and spot views (C, D) of 99mTc MDP planar bone scanin a 57-year-old female, a case of $s / p$ left sided breast-conserving surgery with sentinel lymph node biopsy due to stage IIA (pT1N1M0) breast carcinoma.

\section{REFERENCES}

1. Bauer SB. Anomalies of the upper urinary tract. Campbell's urology. 2002: 1894

2. Lee HP. Crossed unfused renal ectopia with tumor. The Journal of urology. 1949 Feb;61(2):333-9.doi: 10.1016/s0022-5347(17)69071-2.

3. Park JM. Normal and anomalous development of the urogenital system. Campbell's urology. 2002:1742-1743

4. Goel A, Dalela D. Re: Cinman NM, Okeke Z, Smith AD. Pelvic kidney: Associated diseases and treatment. J Endourol 2007; 21: 836-842. Journal of endourology. 2008 Jan 1;22(1):157-8.doi: 10.1089/end.2007.9856.

5. Eid S, Iwanaga J, Loukas M, Oskouian RJ, Tubbs RS. Pelvic kidney: a review of the literature. Cureus. 2018 Jun;10(6).doi: 10.7759/cureus. 2775.
6. Gülsün M, Balkanci F, Cekirge S, Deger A. Pelvic kidney with an unusual blood supply angiographic findings. Surgical and Radiologic Anatomy. 2000 May 1;22(1):59-61.doi: 10.1007/s00276-000-0059-6.

7. Terrone C, Destefanis P, Fiori C, Savio D, Fontana D. Renal cell cancer in presacral ectopic kidney: preoperative diagnostic imaging compared to surgical findings. Urologia Internationalis. 2004;72(2):174-5.doi: $10.1159 / 000075976$

8. Dunnick NR, Sandler CM, Newhouse JH, et al. Congenital anomalies. In:Barry B, Patterson D, DeGeorge T, eds. Textbook of Uroradiology, 3rd ed. Philadelphia: Lippincott Williams \& Wilkins; 2001:15- 48.

9. Britton KE. Diagnostic applications. In: Sampson CB, ed. Textbook of Radiopharmacy Theory and Practice, 3rd ed. Amsterdam: Gordon and Breach Science Publishers. 1999:337-367. 